\title{
La Escritura Perpleja. Hacia Un Posible Uncuentro Entre Crítica Y Videodanza
}

\author{
Susana Temperley
}

as líneas que siguen no buscan hablar sobre videodanza sino sobre escritura de videodanza. El interés en este tópico se origina en algo que comienza a perfilarse como un problema: el hecho de que la videodanza ha encontrado un lugar de emplazamiento y crecimiento prolífico en Latinoamérica y sin embargo, no ha logrado aún despertar el interés de los críticos.

El caso es que la crítica, uno de los metadiscursos más importantes para la vida de géneros y lenguajes, ${ }^{1}$ puede definirse como el extremo del desfasaje entre producción y teorización de videodanza. La existencia aún muy incipiente de textos críticos se hace palpable en comparación con la vitalidad que ha adquirido su objeto de estudio. Se pueden establecer parámetros de este estado de hechos al considerar el contexto de emplazamiento del arte contemporáneo en general, donde la posibilidad de permanencia y de validez del museo como espacio de difusión de las obras consiste en uno de los tópicos de discusión más actuales. En el caso de la crítica, en cambio, la cuestión de validez como medio de difusión no parece formar parte de ningún debate.

Así, ante el palpable retiro de la crítica puede formularse una pregunta que contribuya a abrir el debate: los formatos de la crítica y los interrogantes que ella plantea ¿la habilitan a seguir funcionado como parte del dispositivo metadiscursivo del arte contemporáneo? La ausencia de crítica, aún de forma solapada, sobre artes hibridas como la videodanza puede estar diciendo algo al respecto.

Por otra parte, encontramos la escritura de los propios artistas. La palabra reflexiva de los creadores de videodanza se hace cada vez más frecuente (y fecunda) y se orienta a indagar en la propia obra o teorizar sobre el lenguaje de la videodanza convocando disciplinas como filosofía, epistemología, historia del arte e incluso política. El hecho es que en diferentes circuitos de difusión de las obras (especialmente los festivales) han empezado a abrirse espacios paralelos, destinados solamente a la discusión teórica que, por ahora, se da entre los mismos artistas.

Hoy en día, resulta de suma importancia la existencia de estos textos ya que conforman el único metadiscurso existente sobre videodanza, al tiempo que señalan una carencia estructural de escritos externos a la vorágine de la producción de obras. Podemos hablar así de la teoría proveniente del campo de producción artística como un modo de expresión que si bien es necesario, tiende a generar un hermetismo estructural en el circuito de difusión de obras (a pesar del fluido intercambio a través de páginas web y blogs). En consecuencia, aún se está lejos de la posibilidad de un "mercado" de videodanza, y si bien muchos artistas se encuentran presentando su obra de manera independiente o a través de festivales (cada vez más sofisticados y completos) y muestras itinerantes, los consumidores de videodanza que se generan por cualquiera de estas vías, siguen siendo los mismos artistas. Esta es una de las diferencias cruciales con respecto al Videoarte en general que, de alguna manera está 
siendo explotado en circuitos más "rentables" abiertos por grandes corporaciones del mundo tecnológico (de telefonía principalmente) a través de un neo-mecenazgo que, si bien genera controversias, parece hacerse cargo de un lugar antes vacío. ${ }^{2}$

En síntesis, existe un espacio de teoría desocupado, pero también existe otro, que ha comenzado a madurar y sistematizarse. El punto crucial se encuentra en que la proliferación de escritos provenientes del mismo campo de producción de arte conlleva ciertas ventajas pero no puede reemplazar a la crítica en la especificidad de su rol. ${ }^{3}$

Parece crucial la existencia de una Crítica que abra el campo hacia una reflexión profesional o al menos renovada. Es por eso que en la búsqueda de discusión sobre este tópico surge otra pregunta: si existiera una crítica en videodanza, ¿qué papel le tocaría jugar ante este lenguaje artístico complejo y aún controvertido? Para intentar contestar esta pregunta habrá que tener en cuenta que la existencia de crítica determina en gran medida la importancia de un modo de expresión artístico en la cultura, pues contribuye a la designación de status de lo que critica y lo circunscribe como un espacio autónomo de efectos estéticos.

\section{Ser crítico en videodanza ¿qué significa?}

\subsection{Resolver}

De acuerdo con Danto, las consideraciones estéticas que gobiernan nuestra relación con las obras, e incluso el mismo concepto de Arte, no son ahistóricos y en la actualidad nos encontramos en un momento de cambio radical: "Deberíamos pensar en el arte después del arte, como si estuviéramos emergiendo desde la era del arte a otra cosa, cuya exacta forma y estructura resta ser entendida." ${ }^{4}$

El autor acepta que el arte es paradigmáticamente impredecible pero además, particularmente en este momento, estaríamos frente a una estructura en la que "todo es posible." Así, el arte contemporáneo es demasiado pluralista en intenciones y realizaciones como para permitir ser capturado en una única dimensión y, por ende, la crítica de arte debería ser tan pluralista como el mismo arte posthistórico. ${ }^{5}$

¿Qué tenemos que entender entonces por crítica "posthistórica"? O al menos cabe preguntarnos si es posible postular líneas de abordaje para las obras contemporáneas que permitan seguir definiendo a la crítica como género. ${ }^{6}$ Si la crítica tiene por tarea determinar a qué estructura histórica pertenece la obra que critica, qué significados carga y cuáles son las intenciones que satisface, de entrada se evidencia un efecto de incertidumbre pues estamos frente a una estructura histórica en la que todo es posible, es decir que carecemos de una narrativa maestra que sirva como referencia al crítico para contestar a estas cuestiones.

\section{Pero Danto realiza una salvedad:}

Hoy todo es posible en el sentido en que ciertas cosas no eran posibles para un europeo o un africano en 1890. No obstante estamos encerrados dentro de la historia. No podemos tener el sistema de creencias exclusionistas que impedían a los artistas europeos hacer ídolos y máscaras (...) Pero no hay formas que nos estén prohibidas. Lo único que nos está prohibido es que ellas tengan la especie de significado que tenían cuando nos estaban prohibidas.? 
De acuerdo con esta tesis, la emergencia de una crítica especializada en lenguajes posthistóricos como la Videodanza, se enfrentaría a un objeto de estudio caracterizado por la libertad formal y la novedad e imprevisibilidad en cuanto a su "significado", mientras que la misma crítica sería impensable por fuera de este régimen de creencias del "todo es posible".

Esta posición tan incómoda que se presenta al crítico de arte de la actualidad (llámese contemporáneo o posthistórico, da igual), se evidencia en su propia reflexión. Tal como lo menciona el crítico mexicano Cuauhtémoc Medina:

[El arte actual] tiene que ver con un territorio que asumió (como herencia) el cambio de las posibilidades creativas y de los dilemas entre esas posibilidades creativas y los discursos, imágenes, sonidos y estructuras sociales (...) Los que estamos dentro de este territorio (la crítica) no entendemos más que los que están afuera. Es, más bien que estamos dispuestos a la experiencia de tener que construir nuestra relación con estos objetos una y otra vez, encontrándole placer a ese momento de extrañamiento y aprendizaje.

Nadie nos enseña como elaborarlo. Los llamados especialistas nos quedamos tan perplejos como los demás. A lo mejor ni siquiera podemos hacer algo con lo que se nos está presentando y precisamente en territorio donde podemos establecer diálogos entre nosotros, donde compartimos nuestras excitaciones, donde se montan los discursos, es ese territorio de perplejidad... pero no estamos en la posición de rechazo ante la condición de prácticas que no están aferradas a algún dispositivo ya conocido. ${ }^{8}$

En este escenario, el crítico de videodanza, al asumir su rol, se enfrentaría en primer lugar con la necesidad de "resolver" el dilema de su propia posición pues es posible que no pueda hacer/decir algo con lo que se le presenta como objeto de reflexión y al mismo tiempo no estará en condiciones de rechazarlo para volver a lugar seguro, al de las artes definidas por un dispositivo tradicional.

\subsection{Escribir}

\section{LOS CONCEPTOS}

Ahora bien, el medio donde el crítico resuelve su lugar es la escritura. Y aquí ya aparece otro problema.

Barthes describe el acto de escribir como una suerte de gesto paradójicamente trágico:

Sin duda puedo hoy elegirme tal o cual escritura, y con este gesto afirmar mi libertad, pretender un frescor o una tradición; pero no puedo ya desarrollarla en una duración sin volverme poco a poco prisionero de las palabras del otro e incluso de mis propias palabras. Una obstinada remanencia, que llega de todas las escrituras precedentes y del pasado mismo de mi propia escritura., cubre la voz presente de mis palabras. Toda huella escrita se precipita como un elemento químico, primero transparente, inocente y neutro, en el que la simple duración hace aparecer poco a poco un pasado en suspensión, una criptografía cada vez más densa. ${ }^{9}$

El asunto es que la crítica de videodanza se enfrenta a la tarea de "acompañar" y valorizar cierto objeto - que vive siempre en un presente caracterizado por la ausencia de límites en lo formal- y como ya vimos debe hacerlo dentro de esa misma estructura histórica. El crítico debe efectuar una escritura de su tiempo, de un tiempo que es el mismo que el del artista, ${ }^{10}$ pero por medio de signos que se resisten a decir lo que nunca antes fue dicho. 
La escritura es un lenguaje endurecido que vive sobre sí mismo y de ningún modo está encargado de confiar a su propia duración una sucesión móvil de aproximaciones, sino que, por el contrario, debe imponer, en la unidad y la sobra de sus signos, la imagen de una palabra construida mucho antes de ser inventada. ${ }^{11}$

Así que, para hablar de algo hay que nombrarlo y las palabras designan, definen y delimitan lo posible de ser dicho. El arte podrá ser ese "cualquier cosa" que define Danto pero la crítica, aún la "posthistórica", no puede hablar de ella de cualquier modo. Entonces, partiendo del supuesto de que existe o puede existir alguien tan (irresponsablemente) tenaz como para darse a la tarea de criticar videodanza, ¿cómo puede este sujeto analizar algo que no tiene límites a través de un lenguaje que si los tiene?

En otras palabras, la crítica de videodanza podrá ser una escritura que nace de la perplejidad pero no puede nunca ser imprecisa y ambigua sin violentar su mismo carácter de escritura.

Pues bien, aparece un aspecto donde es posible situarse para comenzar a escapar a tales dificultades: la redefinición permanente de los conceptos. ${ }^{12}$

Ya se sabe que la crítica deberá mantener una visión particular para valorizar diferentes "tipos" ya sea obras centradas en la experimentación tecnológica (el afán por descubrimientos sobre nuevas posibilidades del movimiento y la forma, sin perder el carácter estético del todo) o aquellas que focalizan en la expresividad, la poética y el contenido "humanista" o el contexto social, pero incluso sobre cada una de estas líneas estéticas el crítico se enfrentará , cada vez, a una obra diferente en su forma, su gramaticalidad, en su ser único, que al mismo tiempo y sin precisar cómo, es parte de un conjunto (que a priori sólo se puede caracterizar como "todas las obras como ésta"). Aquí es donde el escritor deberá ser capaz de plantear de entrada una serie de conceptos a través de los cuales pueda decir algo verdadero de una obra de videodanza. Se trata entonces de lograr elaborar esos conceptos que sean capaces de transformarse según cada objeto y cada posición que asuma la escritura frente a éste.

La necesidad de precisión se vuelve abismal (pero no por ello impensable) por eso, cada vez que el crítico aborda un nuevo objeto, debe someter permanentemente a examen las nociones que utiliza en sus escritos—desde qué idea de cuerpo interviene en una videodanza hasta que aspectos de la disciplina se destacan al optar por el término videodanza y "danza para la cámara", e incluso mucho más, pues, ciertamente, será necesario preguntarse acerca de los significados de dispositivo, movimiento y espacio presentes en la obra. Y esto, sólo para ingresar al análisis-y muchas veces, crear otras nuevas especialmente formuladas para el caso.

Una señal, entonces: se hace necesaria la reconceptualización permanente de las nociones que definen y definirán al lenguaje de la videodanza, pero antes, la capacidad para generarlas.

\section{Los lugares comunes}

Luego, otro problema a salvar: la libertad del objeto tiende a repercutir en un abuso del "lugar común" y de las metáforas cristalizadas (catacresis). Estos se presentan como síntoma del debilitamiento de la crítica en casi todos los demás lenguajes artísticos contemporáneos del que la crítica de videodanza aún escapa simplemente por carecer 
de sistematicidad. Sin embargo, al tiempo que enturbian la escritura, los clichés y la estereotipia son parte intrínseca de toda reflexión sobre el arte que surge y busca madurar pues sirven al intercambio, al diálogo entre el crítico y el lector ${ }^{13}$ tal como le son útiles los flotadores al náufrago.

Así, los lugares comunes y las catacresis, también se van esbozando en el caso de la escritura sobre videodanza por ende, detenerse en ellas puede resultar una experiencia interesante: ¿Qué se puede decir a través de fórmulas como: "manipulación de la imagen," "exploración del paisaje de la danza," "apropiación simbólica del espacio," "experiencia dancística," "síntesis entre danza e imagen," "experiencia envolvente...donde el público queda sumergido" y el muy frecuentado "diálogo entre cámara y cuerpo"?

Cristalizaciones en sí mismas que también cristalizan un referente, los lugares comunes "son el efecto, en sus apelaciones argumentativas, de la inercia de la memoria cultural,"14 y aparecen, así, como una voluntad que se orienta hacia un pasado y por lo tanto, en dirección contraria al del lenguaje que es su objeto y que se caracteriza por la complejidad y la búsqueda de especificidad en un contexto impredecible situado en alguna parte entre el presente y el futuro.

Se puede incorporar ahora otra señal: la necesidad de una posición de alerta permanente ante los mismos términos y frases que definen el lenguaje de la crítica y que al tiempo que actúan como índices retóricos de género atentan contra su función de época: el decir algo sobre un objeto que se resiste a ser siquiera nombrado.

\section{Balance}

Determinada por una doble contradicción, una relativa a la pervivencia del lugar común (que tiende a eliminar la reflexión particular y la complejidad, al tiempo que no se puede comunicar nada sin él) y otra basada en la ambigüedad de los conceptos (los signos que limitan lo posible de ser dicho, al tiempo que no hay manera de decir sin ellos), se vislumbra así una posible existencia del metadiscurso sobre videodanza que busca persistir más allá de su propia fatalidad no sólo como Escritura sino también como Crítica, al punto de correr el riesgo de encontrarse en un lugar tan trágico como el del silencio frente a una obra de arte.

Las líneas precedentes dan cuenta de una crítica de videodanza que es aún incipiente, casi ausente, pero que ya presenta vestigios de su condición "posthistórica" pues se enfrenta a la difícil, si no imposible, tarea de ejercitar la escritura para valorar algo que a menudo resulta tan novedoso que no existen aún palabras para calificarlo.

Así, la perplejidad y la escritura son los lugares entre los que se gesta la crítica posthistórica y su objeto. Si la videodanza habilita la perplejidad del espectador, está fecundando el suelo de la crítica y si esta logra transmutar hacia otra cosa -de manera tal que pueda modificar los parámetros que la definieron históricamente-, será posible su constitución como metadiscurso acompañante de la Videodanza.

"La única realidad, decía Foucault no está en las palabras ni en las cosas, sino en los objetos. Los objetos son el resultado de ese encuentro entre las palabras y las cosas"15 


\section{Reflexiones sobre la palabra del artista}

Koldobsky señala que

... las últimas décadas del siglo XX son resultado de las redefiniciones sobre la obra de arte, su práctica y su relación con otras prácticas sociales impulsadas en ese período, es decir que a partir de aquí, no resulta extraña la herencia de una palabra acompañante del autor, más allá de la forma que ésta asuma. ${ }^{16}$

Este es, quizás un punto interesante para indagar en la videodanza en su emplazamiento histórico, e incluso, tangencialmente, el rol "posthistórico"17 del artista de videodanza pues, ya se trate de palabra acompañante o del desenvolvimiento de una función novedosa, el hecho es que, en la actualidad, la teoría abocada a reflexionar sobre dicha práctica estética se encuentra casi exclusivamente bajo el dominio de los propios artistas.

Ahora bien, me referiré aquí a la teoría que podríamos definir como "auto-reflexiva" y que se presenta como "clave de lectura" de la propia obra pero también como guía para la comprensión del lenguaje de la videodanza.

Realizando un paneo general por los escritos latinoamericanos de los últimos años surgen dos grandes grupos orientados por una función definida (que puede o no aparecer explicitada en los mismos discursos):

I) Los trabajos, pertenecientes casi exclusivamente a artistas audiovisuales que navegan en aguas de la videodanza, que se proponen como principal tarea la de indagar sobre las posibilidades técnicas de la cámara (encuadres, movimiento, efectos de edición, etc), en referencia a un tiempo y espacio vinculado con un objeto- cuerpo o con un cuerpo como materia que puede ser manipulada. Estos escritos "organizan"las técnicas de la imagen, probadas en sus propias producciones, así como los efectos logrados en su aplicación, de manera tal que aparecen como una suerte de "manuales" legitimados en la propia experiencia y orientados a la búsqueda de nuevas posibilidades de producción y expansión de los límites del videodanza por sobre lo ya hecho y visto.

II) Aquellos escritos, cuya autoría corresponde mayoritariamente a individuos formados en artes del movimiento, que se plantean cuestiones de índole epistemológica y filosófica sobre concepto de cuerpo, su rol de sujeto u objeto en la relación siempre cambiante y conflictiva con la cámara o la esencia de la videodanza como lenguaje híbrido, entre otras. En muchos de estos ensayos se incluyen citas sobre la propia producción e incluso, la experiencia personal del artista ya sea a modo de ejemplificación de las tesis involucradas o a través de la referencia paratextual. ${ }^{18}$ Con respecto a este último grupo -la referencia paratextual de la propia obra genera el efecto genera una inversión en la relación entre teoría y obra pues la cita transforma el escrito en un complemento de la obra de videodanza, y resulta así útil para descifrar las claves que permitan comprender qué concepto de cuerpo, de movimiento y de Videodanza se juegan en ella o al menos, en el pensamiento del artista durante la creación.

Ahora bien, considerando la pervivencia de éstas dos líneas principales de reflexión teórica, tomamos como referencia la formación institucional canónica (escuela de cine o academia de danza) de los autores- artistas que, sin embargo, navegan en aguas de un arte huidizo, caracterizado por el collage y la fragmentación y lo inter y transdiciplinario. 
Entonces se puede dar lugar a la pregunta: ¿Es realmente autorreflexiva la palabra del artista? o dicho de otro modo ¿el artista está ocupando un lugar en la teoría que se puede ilustrar con la metáfora de "la serpiente que se traga su propia cola"?

La respuesta parece en un principio afirmativa, sin embargo, toma relieve como signo o síntoma en la producción teórica actual de Videodanza, la presencia de un nuevo modelo de artista-escritor que, sin negar el molde de gestación primero (el haberse formado en un arte "puro"), se sitúa para escribir, en ese mismo lugar indefinido que le permite moldear sus obras a través de un código propio.

Así, la cada vez más creciente tendencia a los cruces disciplinarios (en el caso que nos ocupa, los artistas que dejan la cámara para ser performers de sus producciones y a la inversa), repercute en la reflexión teórica y habilita al individuo a hablar de su obra pero "desde otro lugar," no sólo desde la vereda del frente a su experiencia en imagen o en danza, sino desplazándose del centro de la escena (este sujeto se permite incluso, reflexionar sobre la obra de otros e incluso sobre la obra de artistas de otras regiones) buscando siempre algo más allá, de sí mismo y de lo que el campo le ofrece a su capacidad de crear.

\subsection{Balance}

La escritura del artista de videodanza deja entrever, a veces, a un sujeto que sobre la formación canónica primera ha adquirido recursos de otras disciplinas artísticas, reflexión teórica, e incluso en desempeños que en nada aparecen ligados con a la esfera del arte y la estética.

Este artista-escritor es más un habitante libre del mundo y de los lenguajes que un erudito disciplinado. Así es que hay una teoría, la que pertenece a este creador de videodanza - uyo emplazamiento no puede definirse del todo, a caballo entre el manifiesto, la crítica o la simple expresión literaria- que "dice mucho más" en ese intento por ubicar a su propia obra en una narrativa cuya existencia está signada de antemano por la ausencia de una narrativa maestra.

\section{Notes}

1. Steimberg, O Semiótica de los Medios Masivos. Buenos Aires. Atuel (1993).

2. Otra es la apuesta que realizan algunos autores de Videodanza al presentar sus obras en festivales de cine independiente como es el caso de 5(cinco) de Jonahtan Perel, presente en el BAFICI 2008 en la categoría Cortometraje. En este caso podemos pensar en la incursión, con cierto éxito, de este arte híbrido en circuitos discursivos cercanos pero no propios.

3. Nos remitimos al rol que ocupa tradicionalmente la crítica, esto es formar parte fundamental de la cadena de producción, distribución y consumo de los productos artísticos y, en este sentido, ser generadora de público. Ver Traversa Oscar Cine: el significante negado. Buenos Aires. Hachette (1984).

4. Arthur Danto (1997), Después del fin del Arte, Buenos Aires, Paidós, pág 26.

5. Danto esquematiza la narrativa maestra de la historia del arte occidental, como una era de la imitación, seguida de una era de la ideología (donde la filosofía explica el arte), seguida de nuestra era posthistórica "... en la cual podemos decir, calificadamente, que "vale todo" porque es el fin de la narrativa maestra.

6. A partir de las operaciones que realiza, esto es "informar sobre la actualidad del arte y clasificar el discurso focalizado dentro de una serie histórica tanto en lo que se asemeja como en lo que se diferencia de él". Daniela Koldobsky (2005) "Sobre la conflictiva metadiscursividad de las artes visuales a partir de las vanguardias" en AAS: Actas del VI Congreso de la Asociación Argentina de Semiótica, Buenos Aires, pág 3.

7. Ibíd., cita 5, pág 65 . 
8. Cuauthémoc Medina y María Minera "Crítica de Arte Contemporáneo. Conversación entre críticos" (www.letraslibres.com) (registro de audio).

9. Barthes, Roland (2005) El Grado Cero de la Escritura (seguido de Nuevos Ensayos Críticos) Buenos Aires, Siglo XXI Editores 1972, pág 25.

10. Pues así como el artista "debe ser sujeto de su tiempo," . . para que la crítica de arte perdure tiene que haber un individuo reflexionando frente al material que le presenta la cultura de hoy y bajo la presión de demandarle espacio a la cultura contemporánea. Demandarle al tiempo una producción de su tiempo y demandarle al sujeto el tratar de ser un sujeto de su tiempo. Esta es una demanda modernista pero que aún involucra a la crítica de arte actual". Ibíd., cita 9.

11. Ibíd., cita 10, pág 26.

12. Paolo Fabbri señala que"Naturalmente no se puede impedir la idea de que existen algunos signos que para ciertos fines se consideran últimos pero. Pero ello no significa que siempre existan signos últimos, como las palabras, cuya combinación produce frases o textos. Si acaso podemos afirmar lo contrario: sólo existen textos, textos de objetos, no textos de palabras o de referencias, textos de objetos complejos, pedazos de palabras, de gestos, de imágenes, de sonidos, de ritmos, etc., es decir, conjuntos que se pueden segmentar según la necesidad o la urgencia". En Fabbri, P., El Giro Semiótico (1999) Barcelona, Gedisa.

13. A propósito, podemos tomar la caracterización que realiza Oscar Steimberg al referirse al discurso de las vanguardias históricas, abundantes en lugares comunes. El autor se refiere al carácter fatal ya circunscripto en la retórica aristotélica, de la apelación a los lugares comunes en la argumentación. Estos son el reservorio de fórmulas ya aceptadas e instaladas en la memoria pública, a la que debe recurrir el expositor para asentar las premisas de la construcción retórica, y en el mensaje de las vanguardias aparecen como una contradicción interna insalvable. Steimberg, 1999 "Vanguardia y Lugar común", SYC Nro. 9/10 Buenos Aires.

14. Ibíd., cita 14, pág 4.

15. Foucault, M. Las palabras y las cosas. Cita parafraseada de P. Fabrri. Ibíd cita 13, pág 40.

16. Las vanguardias históricas arriesgan la posibilidad de comunicación y construcción de un público, en la medida que el discurso artístico pierde toda previsibilidad. Aquí radica la causa de irrupción a la escena artística de los manifiestos, y a partir de allí la crítica encontrará nuevos despliegues y convivirá con un creciente y expandido discurso acompañante lbíd., cita 7, págs. 3 -4.

17. Podemos decir, entonces que el artista que también teoriza se amolda a la caracterización de Danto "Los artistas hoy están al final de una historia en la cual aquellas estructuras narrativas (las que finalizan en la Modernidad) jugaban un papel, y de este modo pueden ser distinguidos de los artistas que de alguna manera imaginé sentimentalmente como quienes primero emergen como especialistas en una temprana división del trabajo que los habilitó como individuos dotados para asumir las responsabilidades estéticas de la sociedad. . . ". Ibíd., cita 5, pág. 68.

18. Genette Genette Gérard (1989) Palimpsestos. La literatura en segundo grado. Madrid. Taurus 1982. 